\title{
Ginkgolide B Mediated Alleviation of Inflammatory Cascades and Altered Lipid Metabolism in HUVECs via Targeting PCSK-9 Expression and Functionality
}

\author{
Gang Wang $\mathbb{D}^{1},{ }^{1}$ Zhenbin Liu, ${ }^{1}$ Menghu Li, ${ }^{1}$ Yu Li, $^{2}$ Sahir Sultan Alvi, ${ }^{3}$ \\ Irfan Ahmad Ansari, ${ }^{3}$ and M. Salman Khan ${ }^{3}$ \\ ${ }^{1}$ Department of Ulcer and Vascular Surgery, First Teaching Hospital of Tianjin University of Traditional Chinese Medicine, \\ No. 314, Anshanxi Road, Nankai District, Tianjin 300193, China \\ ${ }^{2}$ Department of Pharmaceutical, First Teaching Hospital of Tianjin University of Traditional Chinese Medicine, Tianjin 300193, China \\ ${ }^{3}$ IIRC-5, Clinical Biochemistry \& Natural Product Research Lab, Department of Biosciences, Integral University, \\ Lucknow 226026, UP, India
}

Correspondence should be addressed to Gang Wang; tjtcmwanggang@sina.com

Received 19 February 2019; Revised 13 May 2019; Accepted 26 May 2019; Published 10 June 2019

Academic Editor: Anna Chiarini

Copyright (C) 2019 Gang Wang et al. This is an open access article distributed under the Creative Commons Attribution License, which permits unrestricted use, distribution, and reproduction in any medium, provided the original work is properly cited.

The potential of oxidized-LDL (Ox-LDL) to elicit inflammatory responses in macrophages leading to the atherosclerosis (AS) progression is well known. Since proprotein convertase subtilisin/Kexin-9 (PCSK-9), the posttranslational regulator of LDLreceptor, is associated with elevated LDL in the circulation, the present report was aimed to uncover the ameliorative effects of Ginkgolide B, a terpenic lactone from Ginkgo biloba, against Ox-LDL-induced alterations in cholesterol metabolism in HUVECs. Consequently, our results demonstrated that incubation with Ox-LDL significantly upregulated the PCSK-9 expression in HUVECs, which was significantly downregulated, both at mRNA and protein level, after Ginkgolide B treatment via subsequent suppression of sterol element binding protein (SREBP-2) expression. Moreover, Ginkgolide B-mediated inhibition of PCSK-9 activity was also validated by in silico methods which revealed that it interferes the PSCK-9 interaction with LDL-receptor (LDL-R). Interestingly, Ox-LDL-induced LDL-R expression was further enhanced by Ginkgolide B treatment in HUVECs. Moreover, Ginkgolide B treatment lead to downregulation of lectin-like Ox-LDL receptor (LOX-1) and NADPH oxidase (NOX-4) expression which was upregulated in Ox-LDL-treated HUVECs, along with the attenuation of mitochondrial ROS generation. Furthermore, Ginkgolide B significantly inhibited the augmented expression of intercellular adhesion molecule-1 (ICAM-1) and vascular adhesion molecule-1 (VCAM-1) in Ox-LDL-activated HUVECs. Ginkgolide B also significantly ameliorated the inflammatory response in Ox-LDLactivated HUVECs by suppressing the expression of IL- $1 \alpha$, IL-1 $\beta$, IL- 6 , CXCL-1, CXCL-2, and monocyte chemotactic protein (MCP-1), at mRNA and protein level. Our in vitro and in silico study established that Ginkgolide B alleviated the Ox-LDL-induced inflammatory cascades and altered lipid metabolism in HUVECs by suppressing the PCSK- 9 and, thus, could be established as a treasured alternative therapeutic candidate in the atherosclerosis management.

\section{Introduction}

Atherosclerosis (AS), a leading cause of mortality due to vascular complications, is now considered as chronic inflammation disease of the arterial wall [1, 2]. Although the development of AS is caused by the dysfunction of a number of pathways, oxidized low-density lipoprotein (Ox-LDL) is well reckoned to mediate endothelial dysfunction as well as to accelerate the proliferation and vibrations of smooth muscle cells (SMCs), monocytes, macrophages, and fibroblasts, in addition to the oxidative stress response and cell damage of endothelial cells (ECs) [3], eventually leading to AS plaque formation. Proprotein convertase subtilisin/kexin 9 (PCSK-9), a hepatic protease, is expressed in various cells types/tissues in human and other mammals with maximum expression in hepatocytes $[4,5]$. Numerous earlier reports 
uncovered that PCSK-9 plays a major role in cholesterol homeostasis as it elevates the LDL-C level in the circulation via degrading the LDL-receptor (LDL-R) in the hepatocyte cell membrane $[5,6]$. It has also been shown to be involved in the Ox-LDL-induced apoptosis of human umbilical vein endothelial cells (HUVECs) [7].

Since LDL-C has been proved to be the most influential risk factor for onset of AS, several studies attempted to establish an association between cholesterol homeostasis and inflammation. Based on the above physiological effects, PCSK-9 is thought to be the major regulator of the LDL-C load in the circulation and hepatic cholesterol homeostasis $[8,9]$. PCSK-9 has also been detected in the AS plaque and the LDL-R abundance in macrophages is negatively influenced by SMCs-derived PCSK-9 $[9,10]$. Inflammation has also been found to markedly alter the lipoprotein and triglyceride-rich lipoprotein (TGRLs) metabolism as well as stimulating PCSK-9 expression [5]. More importantly, hypercholesterolemia and related cardiovascular manifestations, i.e., AS, are now widely accepted as inflammatory diseases [11].

Lectin-like Ox-LDL receptor-1 (LOX-1), a scavenger receptor, reckoned to internalize the Ox-LDL and is stimulated in distinct inflammatory complications, including AS $[5,12,13]$. A study in cultured aortic ECs and SMCs has suggested an interesting cross-talk between PCSK-9 and LOX-1 expression, as both PCSK-9 and LOX-1 stimulated each other, predominantly under inflammatory state [5].

An interaction between ECs and inflammatory cells has the capability to trigger the production inflammatory cytokines [14], whereas the PCSK-9 has also been found to elicit an inflammatory response via secretion of inflammatory cytokines and the chemokines [9]. Thus, resulting crosstalk between these cells may play a pivotal role in the development of inflammatory states. Thus, retarding the Ox-LDL-stimulated inflammatory cascades and altered lipid metabolism in ECs could be a potential line of attack in preventing the progression of AS. Ginkgolide B, a diterpenoid derived from Ginkgo biloba, has been known for its extensive pharmacological effects. It has been implied as a specific platelet activating factor (PAF) receptor antagonist and prevents PAF-mediated platelet activation $[15,16]$. Moreover, a recent report has described the protective role of Ginkgolide B in AS, but the detailed mechanism of action of this compound including its effect on PCSK-9-LDL-R pathway and inflammation is still not elucidated completely [17]. Therefore, the present report was undertaken to assess the effect of Ox-LDL on PCSK-9-LDL-R pathway, oxidative stress, and proinflammatory cascade in HUVECs and its alleviation by Ginkgolide B.

\section{Materials and Methods}

2.1. Reagents and Assay Kits. Ginkgolide B and 2',7'-dichlorodihydrofluorescein diacetate (DCFH-DA) were procured from Sigma Aldrich, USA. Ambion's RNAqueous ${ }^{\mathrm{TM}}$ Total RNA Isolation Kit, Verso cDNA synthesis kit, and DyNAmo Color Flash SYBR Green qPCR Kits were bought through
Thermo Fisher Scientific, USA. Dulbecco's Modified Eagle's Medium (DMEM), FBS, and other analytical-grade chemicals were purchased from HiMedia Pvt. Ltd., Mumbai, India.

2.2. Preparation of $O x-L D L$. Human LDL was isolated as described previously and subjected to oxidation by incubation with $5 \mathrm{mM} \mathrm{CuSO} 4$ [18]. The success of LDL oxidation was confirmed by TBARS assay [19, 20]. Thus, prepared $\mathrm{Ox}-\mathrm{LDL}$ was filtered and maintained at $4^{\circ} \mathrm{C}$. The protein concentration of LDL was assayed using Bradford's method [21].

2.3. Human Umbilical Vein Endothelial Cells (HUVECs) Culture. The HUVECs were obtained from American Type Culture Collection (ATCC), USA. Cells were cultured under standard culture conditions in DMEM containing $10 \%$ heatinactivated FBS, $2 \mathrm{mM}$ glutamine, and antibiotics $(100 \mathrm{U} / \mathrm{ml})$. To study the impact of oxidatively modified-LDL on various biochemical and molecular parameters, HUVECs were incubated with Ox-LDL $(25-100 \mu \mathrm{g} / \mathrm{ml})$, whereas to evaluate the antiatherogenic potential of Ginkgolide B, the cells were pretreated $(24 \mathrm{hr})$ with varying concentrations of Ginkgolide B $(20-100 \mu \mathrm{g} / \mathrm{ml})$ followed by induction with OxLDL $(75 \mu \mathrm{g} / \mathrm{ml})$ for $24 \mathrm{hr}$.

2.4. RNA Extraction and Quantitative Real-Time PCR ( $q R T$ $P C R)$. The Ambion's RNAqueous ${ }^{\mathrm{TM}}$ Total RNA Isolation Kit was applied to isolate the total cellular RNA (tcRNA), after harvesting the above cultured HUVECs, followed by cDNA synthesis from tcRNA using a Verso cDNA synthesis kit. qRT-PCR was run on the ABI-7500 real-time PCR machine (Applied Biosystems) using DyNAmo Color-Flash SYBR Green qPCR Kit according to the manufacturer's instructions. Specific primers used in GRT-PCR analysis have been listed in Table $1[17,22,23]$. GAPDH was used as internal control to normalize relative mRNA levels for all genes. Differences in the expression of various genes were calculated using $2^{-\Delta \Delta \mathrm{Ct}}$ method.

2.5. Cholesterol Quantitation Assay. To uncover the ameliorative ability of Ginkgolide $B$ on cholesterol accumulation in ECs, above HUVECs were collected and their total cholesterol (TC) and free cholesterol (FC) were quantified by Cholesterol Quantitation Kit supplied by Sigma-Aldrich, USA.

2.6. Cell Lysate Preparation. The above harvested HUVECs cells were lysed using lysis buffer, containing protease inhibitors, EDTA, and Tris- $\mathrm{HCl}$ followed by sonication and centrifugation at $15,000 \mathrm{~g}$ for $5 \mathrm{~min}$. Thus, obtained lysates were used for the quantification of various proteins.

2.7. Enzyme Linked Immunosorbant Assay (ELISA). ELISA was used to determine the protein level of PCSK-9, cytokines (IL- $1 \alpha$, IL-1 $\beta, \&$ IL-6), and chemokines (MCP-1, CXCL-1, and CXCL-2). Various ELISA kits were supplied by Abcam, United Kingdom. 
Table 1: Primers used in this study for gene expression analysis.

\begin{tabular}{|c|c|c|}
\hline Gene name & Primer & Sequences (from 5' to 3') \\
\hline \multirow{2}{*}{ SREBP-2 } & $\mathrm{F}$ & CCCTGGGAGACA TCGACGA \\
\hline & $\mathrm{R}$ & CGTTGCACTGAAGGGTCCA \\
\hline \multirow{2}{*}{ PSCK-9 } & $\mathrm{F}$ & CCTGCGCGTGCTCAACT \\
\hline & $\mathrm{R}$ & GCTGGCTTTTCCGAAACTCT \\
\hline \multirow{2}{*}{ LDL-R } & $\mathrm{F}$ & GTGTCACAGCGGCG \\
\hline & $\mathrm{R}$ & CGCACTCTTTGATG \\
\hline \multirow{2}{*}{ NOX-4 } & $\mathrm{F}$ & TGTTGGATGACTGGAAACCA \\
\hline & $\mathrm{R}$ & TGGGTCCACAACAGAAAACA \\
\hline \multirow{2}{*}{ LOX-1 } & $\mathrm{F}$ & GCTGCTATGACTCTGGTCAT \\
\hline & $\mathrm{R}$ & TACGATCCTGCTGAGTAAGG \\
\hline \multirow{2}{*}{ ICAM-1 } & $\mathrm{F}$ & GGCCGGCCAGCTTATACAC \\
\hline & $\mathrm{R}$ & TAGACACTTGAGCTCGGGCA \\
\hline \multirow{2}{*}{ VCAM-1 } & $\mathrm{F}$ & TCAGATTGGAGACTCAGTCATGT \\
\hline & $\mathrm{R}$ & АСТССТСАССТТСССGCTC \\
\hline \multirow{2}{*}{ IL- $1 \alpha$} & $\mathrm{F}$ & TTCССТСАAССАAАСТАТАТ \\
\hline & $\mathrm{R}$ & ACGGGCTGGTCTTCTCCTTG \\
\hline \multirow{2}{*}{ IL- $1 \beta$} & $\mathrm{F}$ & CTCATTGTGGCTGTGGAGAA \\
\hline & $\mathrm{R}$ & CACACACCAGCAGGTTATCA \\
\hline \multirow{2}{*}{ IL-6 } & $\mathrm{F}$ & TCTCTCCGCAAGAGACTTCCA \\
\hline & $\mathrm{R}$ & ATACTGGTCTGTTGTGGGTGG \\
\hline \multirow{2}{*}{ MCP-1 } & $\mathrm{F}$ & TTCTGTGCCTGCTGCTCATA \\
\hline & $\mathrm{R}$ & CAGATCTCCTTGGCCACAAT \\
\hline \multirow{2}{*}{ CXCL-1 } & $\mathrm{F}$ & TCATCGAAAAGATGCTGAACA \\
\hline & $\mathrm{R}$ & TTCAGGAACAGCCACCAGT \\
\hline \multirow{2}{*}{ CXCL-2 } & $\mathrm{F}$ & CATCGAAAAGATGCTGAAAAATG \\
\hline & $\mathrm{R}$ & TTCAGGAACAGCCACCAATA \\
\hline \multirow{2}{*}{ GAPDH } & $\mathrm{F}$ & CAACAGCCTCAAGATCATCAGCA \\
\hline & $\mathrm{R}$ & TGGCATGGTCTGTGGTCATGAGT \\
\hline
\end{tabular}

2.8. Measurement of Intracellular ROS Generation. The intracellular ROS level was measured by previously described DCFH-DA method [24]. Briefly, $1 \times 10^{4}$ cells were pretreated with Ginkgolide B $(20,40,80$, and $100 \mu \mathrm{g} / \mathrm{ml})$ for $24 \mathrm{~h}$ and then treated with Ox-LDL $(75 \mu \mathrm{g} / \mathrm{ml})$ for next $6 \mathrm{~h}$. After incubation, the cells were treated with DCFH-DA $(10 \mu \mathrm{M})$ for half of an hour at $37^{\circ} \mathrm{C}$ followed by measurement of fluorescence intensity (FI) (excitation and emission wavelength of 485 \& $528 \mathrm{~nm}$, respectively).

2.9. Molecular Informatics Studies of Ginkgolide B against PCSK-9 and Its Interaction with EGF-A Complex. The PCSK-9 structure was obtained from the PDB (ID: 2p4e) (http://www.rcsb.org). The sdf files of Ginkgolide B (PubChem ID: 6324617) and Atorvastatin (PubChem ID: 60823) were retrieved from PubChem database (https:// pubchem.ncbi.nlm.nih.gov/). Molecular docking analysis was executed by using AutoDock (version; 4.2) [19]. EGF-A like repeats of LDL-R in complex with PCSK-9 were also retrieved from PDB (PDB ID: 3BPS). 3D conformation of PCSK-9 from this complex was removed prior to proteinprotein interaction (PPI) analysis [19]. The PPI analysis of
Ginkgolide B-PCSK-9 with EGF-A-like repeats of LDL-R was performed by ZDOCK server (http://zdock.umassmed.edu/).

2.10. Statistical Analysis. The assays were performed in triplicate and the results of these experiments have been denoted as the mean \pm standard error of means (SEM). The Student's $t$-test was used to calculate p-values between two groups, whereas, for comparing multiple groups, one-way analysis of variance (ANOVA) was performed, which was followed by Post Hoc Tukey-Kramer multiple comparisons test. All the statistical analyses were carried out using GraphPad Prism version 4.02 (GraphPad Software, San Diego, USA). $\mathrm{p}<0.05$, $\mathrm{p}<0.01$, and $\mathrm{p}<0.001$ were considered statistically significant, highly significant, and very highly significant, respectively, whereas $\mathrm{p}>0.05$ was considered as statistically nonsignificant. The level of significance for each data set (with different $p$ values) has been mentioned in respective figure legends using distinct symbols.

\section{Results}

3.1. Ginkgolide B Amends the Ox-LDL-Induced Altered Expression of PCSK-9, SREBP-2, and LDL-R in HUVECs. First of 


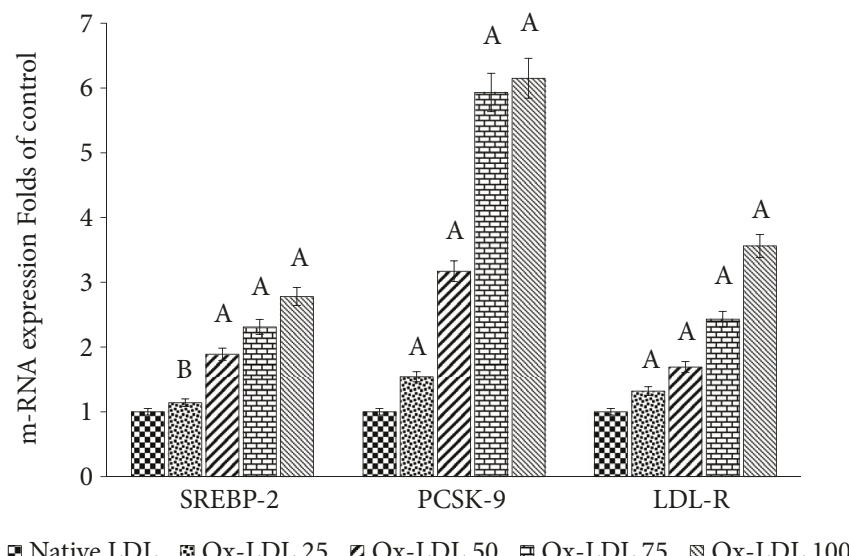

(a)

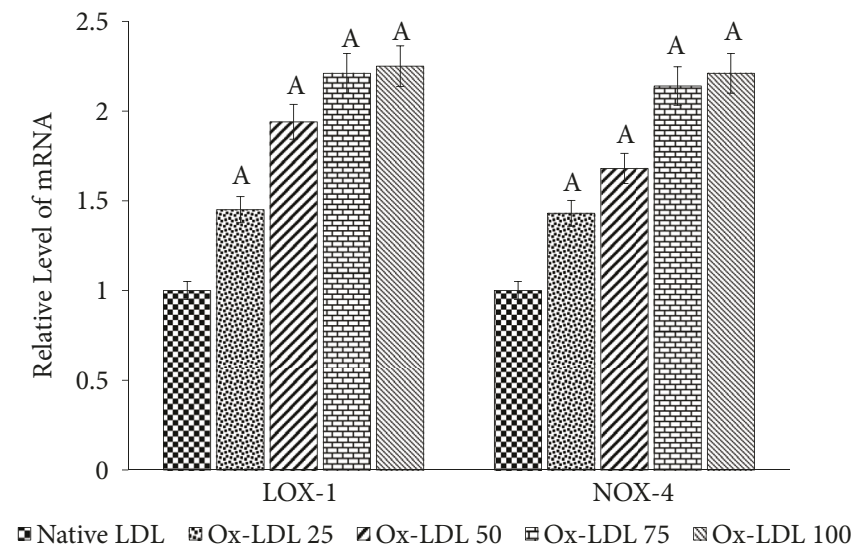

(c)

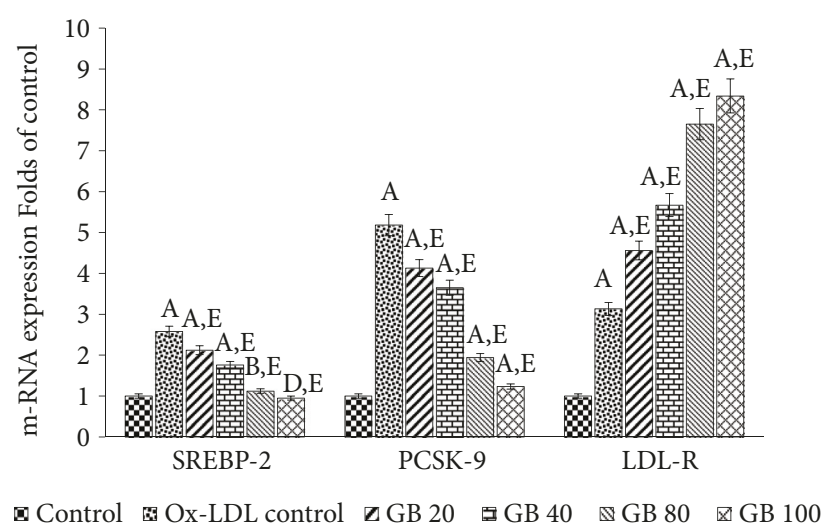

(b)

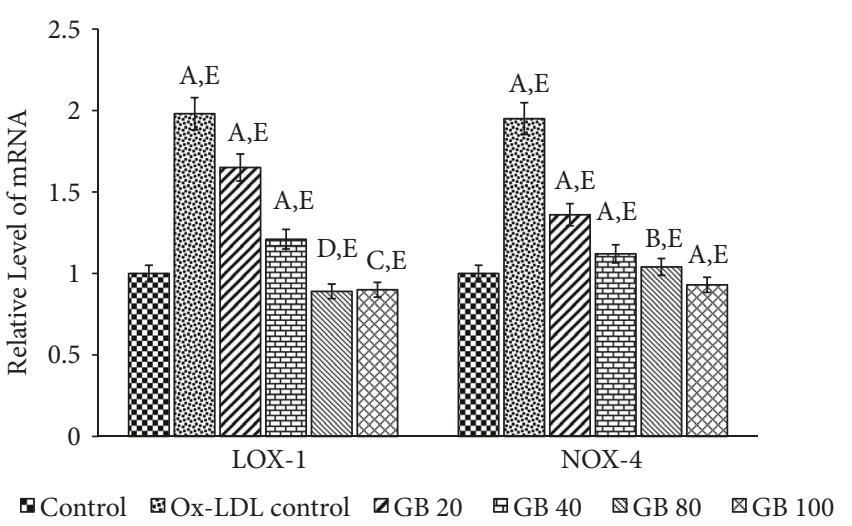

(d)

Figure 1: (a) Ox-LDL alters the expression of SREBP-2, PCSK-9, and LDL-R in HUVECs. The HUVECs were cultured in Dulbecco's Modified Eagle's Medium (DMEM) containing $10 \%$ heat-inactivated FBS, $2 \mathrm{mM}$ glutamine, and antibiotics at $37^{\circ} \mathrm{C}$ in a humidified $5 \% \mathrm{CO}_{2}$ atmosphere. Thus, cultured cells were either treated with native LDL or Ox-LDL at different concentrations 25, 50, 75, and 100 $\mu \mathrm{g} / \mathrm{ml}$ designated as Ox-LDL 25, Ox-LDL 50, Ox-LDL 75, and Ox-LDL 100, respectively, for gene expression analysis. Significantly different from native LDL at ${ }^{\mathrm{A}} \mathrm{p}<0.001$. Nonsignificantly different from native LDL at ${ }^{\mathrm{B}} \mathrm{p}>0.05$. (b) Ginkgolide B amends the $O x-L D L$-induced altered expression of SREBP-2, PCSK-9, and LDL-R in HUVECs. The HUVECs were pretreated with $20-100 \mu \mathrm{g} / \mathrm{ml}$ of Ginkgolide B (designated as GB 20, GB 40, GB 80, and GB $100)$ for $24 \mathrm{~h}$ and then all the groups except control were exposed to Ox-LDL $(75 \mu \mathrm{g} / \mathrm{ml})$ for another $24 \mathrm{~h}$ followed by m-RNA extraction for qRT-PCR analysis. Significantly different from control HUVECs at ${ }^{A} \mathrm{p}<0.001$. Significantly different from control HUVECs at ${ }^{\mathrm{B}} \mathrm{p}<0.01$. Significantly different from control HUVECs at ${ }^{C} p<0.05$. Nonsignificantly different from control HUVECs at ${ }^{D} p>0.05$. Significantly different from Ox-LDL at ${ }^{\mathrm{E}} \mathrm{p}<0.001$. (c) Ox-LDL upregulates the expression of LOX-1 and NOX-4 in HUVECs. The HUVECs were cultured and treated with Ox-LDL as described in (a). Significantly different from native LDL at ${ }^{\mathrm{A}} \mathrm{p}<0.001$. (d) Ginkgolide B downregulates the Ox-LDL-induced expression of LOX-1 and NOX-4 in HUVECs. The HUVECs were cultured and treated with Ginkgolide B and Ox-LDL as described in (b). Significantly different from control HUVECs at ${ }^{A} \mathrm{p}<0.001$. Significantly different from control HUVECs at ${ }^{\mathrm{B}} \mathrm{p}<0.01$. Significantly different from control HUVECs at ${ }^{C} p<0.05$. Nonsignificantly different from control HUVECs at ${ }^{D} p>0.05$. Significantly different from Ox-LDL at ${ }^{\mathrm{E}} \mathrm{p}<0.001$. All the values in (a), (b), (c), and (d) have been expressed as mean \pm SEM of three independent experiments.

all, we set out to examine whether Ox-LDL affects PSCK9 expression in HUVECs. In this context, we observed a dose-dependent overexpression of PCSK-9 in HUVECs by Ox-LDL with highest expression at 75 and $100 \mu \mathrm{g} / \mathrm{ml}(5.93$ and 6.15 folds of control, respectively) (Figure 1(a)). Then, we examined the ameliorative effect of Ginkgolide B on Ox-LDLstimulated PSCK-9 overexpression in HUVECs. As shown in Figure 1(b), the incubation with Ox-LDL $(75 \mu \mathrm{g} / \mathrm{ml})$ induced an increase in PCSK-9 mRNA expression in HUVECs (5.18 folds), when matched to only DMSO treated control cells, whereas the pretreatment with $20,40,80$, and $100 \mu \mathrm{g} / \mathrm{ml}$ of Ginkgolide B suppressed the expression of PCSK-9 in HUVECs (up to 4.13, 3.65, 1.94, and 1.23 folds of control, respectively).

On the other hand, sterol regulatory element binding protein-2 (SREBP-2) is an important transcriptional regulator of PCSK-9 expression. Thus, we further investigated whether Ox-LDL affects SREBP-2 expression in HUVECs. Interestingly, a dose-dependent expression of SREBP-2 was induced in HUVECs by Ox-LDL and was found to be highly 
expressed at 75 and $100 \mu \mathrm{g} / \mathrm{ml}$ of doses (2.31 and 2.78 folds of control, respectively) (Figure 1(a)). Then, we analyzed the impact of Ginkgolide B pretreatment on the expression of SREBP-2 in the same cells incubated with oxidatively modified LDL. As shown in Figure 1(b), the incubation of HUVECs with modified-LDL $(75 \mu \mathrm{g} / \mathrm{ml})$ upregulated the SREBP-2 expression (2.58 folds), when matched to only DMSO-treated control HUVECs, while the pretreatment of cells with $20,40,80$, and $100 \mu \mathrm{g} / \mathrm{ml}$ of Ginkgolide B downregulated the SREBP-2 mRNA expression by 2.12, 1.76, 1.12, and 0.95 folds of control, respectively. Thus, our results have also shown that Ginkgolide-mediated suppression of PCSK9 expression was achieved via SREBP-2 downregulation in HUVECs.

Similarly, we further analyzed that whether Ox-LDL affects LDL-R expression in HUVECs and reported a dosedependent upregulation of LDL-R expression in HUVECs by Ox-LDL with the maximum expression at 75 and $100 \mu \mathrm{g} / \mathrm{ml}$ (2.43 and 3.56 folds of control, respectively) (Figure 1(a)). Further, we determined the potential of Ginkgolide $B$ to ameliorate the LDL-R expression also in Ox-LDL-challenged HUVECs. As shown in Figure 1(b), the incubation with Ox-LDL $(75 \mu \mathrm{g} / \mathrm{ml})$ resulted in an upregulation in LDL-R expression (3.13 folds), when equated to only DMSO-treated HUVECs, whereas the Ginkgolide B pretreatment further augmented the LDL-R expression (up to 4.56, 5.67, 7.65, and 8.34 folds of control, respectively). Thus, our findings showed an interesting phenomenon that Ginkgolide B treatment augmented the expression of LDL-R along with suppression of PCSK-9.

3.2. Ginkgolide B Suppressed the LOX-1 and NOX-4 Expression in HUVECs. Further, we analyzed the effect of Ox-LDL on the LOX-1 expression and reported that the LOX-1 expression was upregulated by 2.21 and 2.25 folds in 75 and $100 \mu \mathrm{g} / \mathrm{ml}$ Ox-LDL-treated cells, respectively (Figure 1(c)). Later on, we examined the protective impact of Ginkgolide B on Ox-LDLinduced LOX-1 expression. As represented in Figure 1(d), OxLDL upregulated the LOX-1 expression by 1.98 folds, while the Ginkgolide B pretreated cells $(20,40,80$, and $100 \mu \mathrm{g} / \mathrm{ml})$ exhibited downregulation in the LOX-1 expression by 1.65 , $1.21,0.89$, and 0.90 folds, respectively.

On the other hand, NADPH oxidase-4 (NOX-4) is a well-reckoned precursor of ROS in various cells; therefore, we determined the stimulatory role of Ox-LDL on NOX-4 expression. Similar to our assumptions, NOX-4 expression was found to be upregulated in all the Ox-LDL-treated cells with maximum upregulation of 2.14 and 2.21 folds at 75 and $100 \mu \mathrm{g} / \mathrm{ml}$, respectively (Figure $1(\mathrm{c})$ ). Then, we analyzed the modulatory impact of our test compound on Ox-LDLtriggered NOX-4 expression in the same cells. As shown in Figure 1(d), Ginkgolide B pretreatment at 20, 40, 80, and $100 \mu \mathrm{g} / \mathrm{ml}$ significantly downregulated the mRNA level of NOX-4 by $1.36,1.12,1.04$, and 0.93 folds, respectively. Thus, our findings signify that Ginkgolide B mediated inhibition of ROS in Ox-LDL-supplemented HUVECs may be linked to the suppression of NOX-4 expression in HUVECs.
3.3. Ginkgolide B Inhibited the Ox-LDL-Stimulated Lipid Deposition. In an attempt to determine the protective effect of the Ginkgolide B against Ox-LDL-induced lipid deposition in HUVECs, our data illustrated an increase in FC (from $0.68 \mu \mathrm{g} / \mu \mathrm{l}$ to $8.49 \mu \mathrm{g} / \mu \mathrm{l})$, whereas the level of TC was also found to rise (from $3.41 \mu \mathrm{g} / \mu \mathrm{l}$ to $32.25 \mu \mathrm{g} / \mu \mathrm{l}$ ) in Ox-LDLchallenged $(75 \mu \mathrm{g} / \mathrm{ml})$ HUVECs, when matched to respective control cells. Conversely, Ginkgolide B supplementation (20, 40,80 , and $100 \mu \mathrm{g} / \mathrm{ml}$ ) significantly lowered the accumulation of TC and FC in HUVECs incubated with Ox-LDL (Figure 2(a)).

3.4. Ginkgolide B Reduces the Level of PCSK-9 in Ox-LDLStimulated HUVECs. We intended to uncover that whether Ox-LDL influences the protein level of PCSK-9 in HUVECs and we observed that a dose-dependent increase in the protein level of PCSK-9 induced in HUVECs by Ox-LDL with maximum PCSK-9 protein level at 75 and $100 \mu \mathrm{g} / \mathrm{ml}$ of OxLDL (15.32 and $21.79 \mathrm{ng} / \mathrm{ml}$, respectively), when compared to the HUVECs treated with DMSO only (Figure 2(b)). Furthermore, the pretreatment of Ginkgolide B (20, 40, 80, and $100 \mu \mathrm{g} / \mathrm{ml}$ ) also suppressed the protein level of PCSK-9 in HUVECs with a maximum setback in 80 and $100 \mu \mathrm{g} / \mathrm{ml}$ Ginkgolide B-treated HUVECs (Figure 2(c)).

3.5. Ginkgolide B Suppressed the Ox-LDL-Induced Increase of ROS Production. In this experiment, we first determined whether Ox-LDL affects ROS production in HUVECs or not. The data, presented in Figure 3(a), showed a dosedependent augmentation of ROS generation in Ox-LDLtreated HUVECs and was found to be raised to maximum $89.35 \%$ and $98.45 \%$, as compared to control, at 75 and $100 \mu \mathrm{g} / \mathrm{ml}$ of doses, respectively. Further, the protective action of Ginkgolide B against Ox-LDL-induced elevation of ROS level in HUVECs was also determined. The ROS production was found to be significantly increased (up to $84.96 \%$ ) in HUVECs after the exposure of Ox-LDL $(75 \mu \mathrm{g} / \mathrm{ml})$, when compared to control. As represented in Figure 3(b), the Ginkgolide B supplementation significantly diminished the Ox-LDL induced ROS production with maximum restoration in $100 \mu \mathrm{g} / \mathrm{ml}$ Ginkgolide B-treated HUVECs $(2.3 \%$ of control).

3.6. Ginkgolide $B$ Inhibited the Expression of Adhesion Molecules. The results, presented in Figure 3(c), showed that expression of ICAM-1 and VCAM-1 was highly expressed after incubation with Ox-LDL at doses of 75 and $100 \mu \mathrm{g} / \mathrm{ml}$ (1.76 and 2.74 folds of control for ICAM-1; 1.86 and 2.34 folds of control for VCAM-1, respectively). Moreover, an enhanced expression of ICAM-1 and VCAM-1 mRNA was observed when cells were incubated with Ox-LDL $(75 \mu \mathrm{g} / \mathrm{ml})$ by 1.63 and 1.73 folds of control, respectively. These changes in the expression of these adhesion molecules were significantly restored in Ginkgolide B treated HUVECs (Figure 3(d)). The suppression of both ICAM-1 and VCAM-1 expression by Ginkgolide B indicates that this compound could alleviate Ox-LDL-induced endothelial dysfunction. 


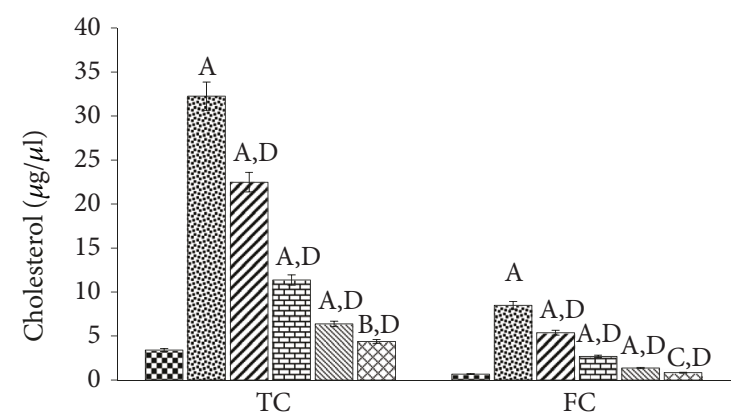

- Control Ox-LDL control aGB 20 므 40 GB 80 GB 100

(a)

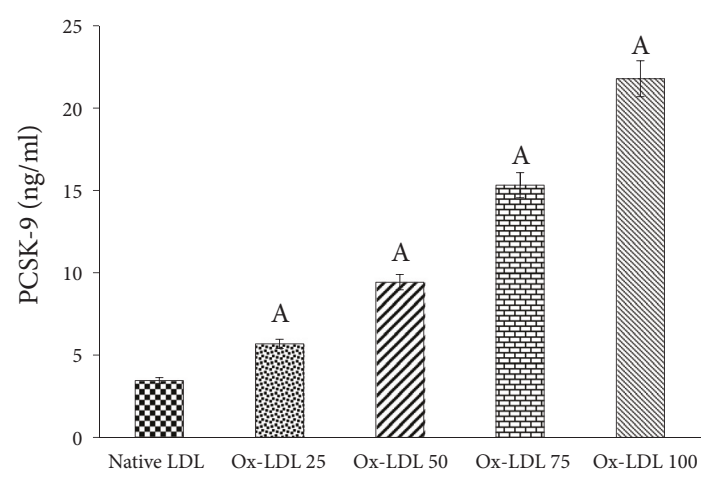

(b)

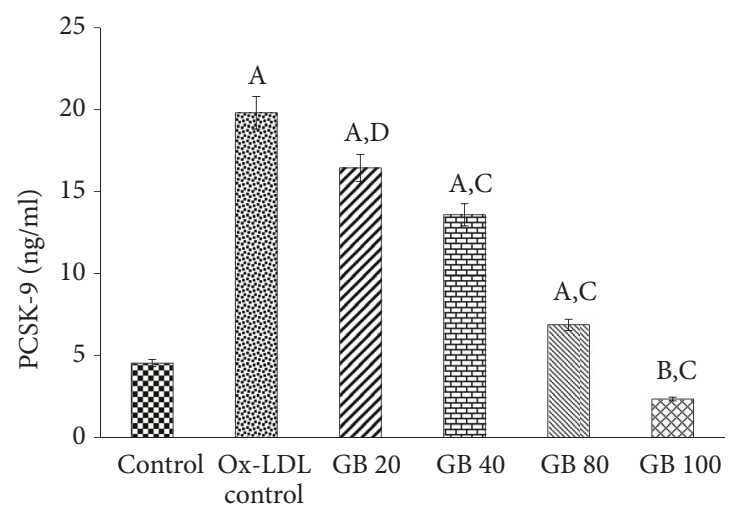

(c)

FIgURE 2: (a) Ginkgolide B decreases Ox-LDL-induced total cholesterol and free cholesterol deposition in HUVECs. The HUVECs were cultured in DMEM containing $10 \%$ heat-inactivated FBS, $2 \mathrm{mM}$ glutamine, and antibiotics at $37^{\circ} \mathrm{C}$ in a humidified $5 \% \mathrm{CO}_{2}$ atmosphere. Thus, cultured cells were pretreated with $20-100 \mu \mathrm{g} / \mathrm{ml}$ of Ginkgolide B for $24 \mathrm{~h}$ and then exposed to Ox-LDL $(75 \mu \mathrm{g} / \mathrm{ml})$ for another $24 \mathrm{~h}$ for quantitation of TC and FC. Significantly different from control HUVECs at ${ }^{A} \mathrm{p}<0.001$. Significantly different from control HUVECs at ${ }^{\mathrm{B}} \mathrm{p}<0.01$. Nonsignificantly different from control HUVECs at ${ }^{C} \mathrm{p}>0.05$. Significantly different from Ox-LDL at ${ }^{\mathrm{D}} \mathrm{p}<0.001$. (b) Ox-LDL raises the level of PCSK-9 in HUVECs. The cultured HUVECs cells were either treated with native LDL or Ox-LDL (25, 50, 75, and $100 \mu \mathrm{g} / \mathrm{ml})$ for determination of PCSK9 level by ELISA. Significantly different from native LDL at ${ }^{\mathrm{A}} \mathrm{p}<0.001$. (c) Ginkgolide B lowers the Ox-LDL-induced PCSK-9 level in HUVECs. The cultured HUVECs cells were pretreated with 20-100 $\mu \mathrm{g} / \mathrm{ml}$ of Ginkgolide B for $24 \mathrm{~h}$ and then exposed to Ox-LDL (75 $\mu \mathrm{g} / \mathrm{ml})$ for another $24 \mathrm{~h}$ for quantitation of PCSK-9 via ELISA. Significantly different from control HUVECs at ${ }^{\mathrm{A}} \mathrm{p}<0.001$. Significantly different from control HUVECs at ${ }^{B} p<0.01$. Significantly different from Ox-LDL at ${ }^{D} p<0.001$. Significantly different from Ox-LDL at ${ }^{E} p<0.01$. All the values in (a), (b), and (c) have been expressed as mean \pm SEM of three independent experiments.

3.7. Ginkgolide B Suppressed the Ox-LDL-Induced Expression of Inflammatory Cytokines in HUVECs. We also investigated the impact of Ox-LDL-mediated oxidative stress on the expression of various cytokines, i.e., Interleukins (IL)- $1 \alpha$, $1 \beta$, and 6 as well as chemokines, i.e., monocyte chemotactic protein (MCP-1) and chemokine (C-X-C motif) ligand (CXCL-1 and 2). The incubation with Ox-LDL $(75 \mu \mathrm{g} / \mathrm{ml})$ resulted in the overexpression of (IL)- $1 \alpha, 1 \beta, 6$, MCP-1, CXCL-1, and CXCL- 2 by $4.98,3.79,5.87,4.56,6.34$, and 5.47 folds, respectively. Such elevations in the mRNA expression of inflammatory mediators were markedly restored in Ginkgolide B pretreated cells in comparison to untreated cells (Figure 4(a)). On the other hand, the protein level of these cytokines was found to be upregulated in HUVECs after incubation with Ox-LDL $(75 \mu \mathrm{g} / \mathrm{ml})$, assayed by ELISA. The protein level of the above-mentioned inflammatory mediators was greatly normalized in Ginkgolide B pretreated cells (Figure 4(b)).

3.8. Ginkgolide B Alters PCSK-9 Interaction with EGF-A. Our computational approach demonstrated that the binding energies ( $\Delta \mathrm{G}$ values) for Ginkgolide $\mathrm{B}$ and Atorvastatin, when complexed with PCSK-9, were -7.13 and $-7.02 \mathrm{Kcal} / \mathrm{mol}$, respectively, whereas the inhibition constant was found to be 5.92 and $7.16 \mu \mathrm{M}$, respectively. The binding of Ginkgolide B with the active site of PCSK-9 involved its interaction with the Ser329, Pro331, Arg357 Arg458, Val460, Trp461, Ser462, Ala463, Val474, Ala475, and Arg476 amino acid residues (Figure 5(a)), whereas Atorvastatin interaction with PCSK9 involved the interaction with Arg306, Pro331, Glu332, Arg357, Asp360, Arg412, Arg458, Val460, Trp461, Ser462, ALA463, Val474, Ala475, Arg476, Cys477, Ala478, and 


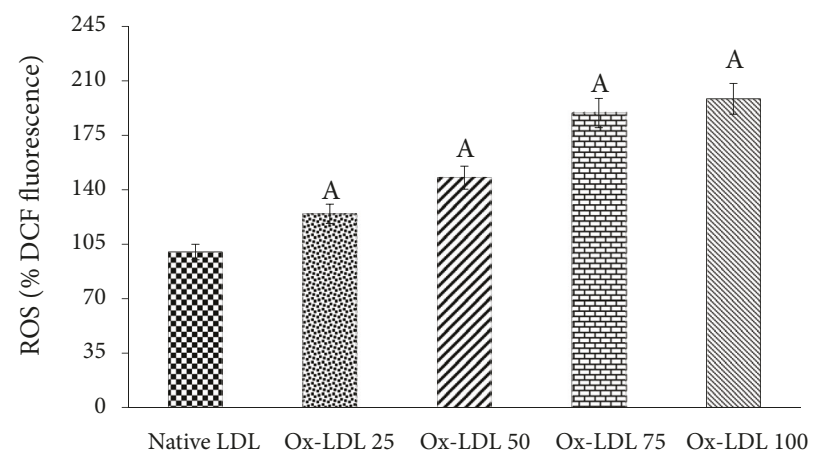

$\square$ Native LDL $\approx$ Ox-LDL $25 \square$ Ox-LDL 50 تOx-LDL $75 \bowtie$ Ox-LDL 100

(a)

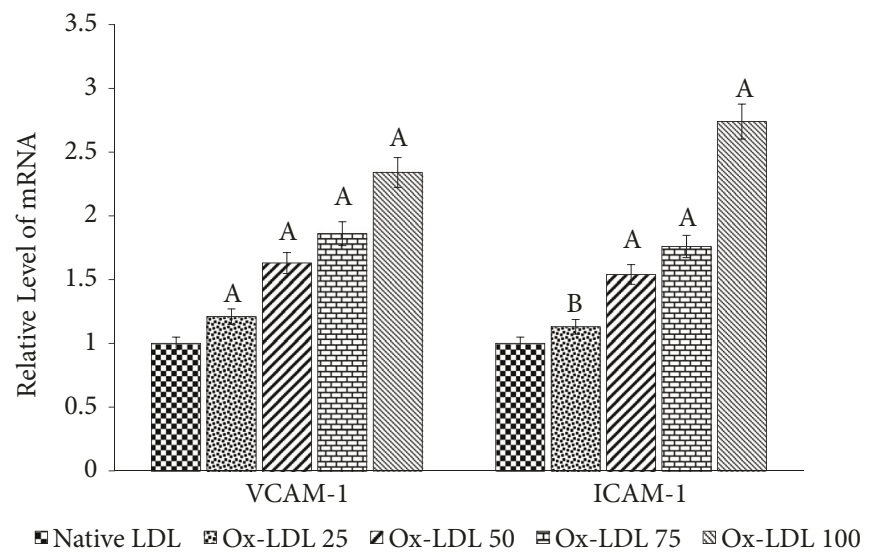

(c)

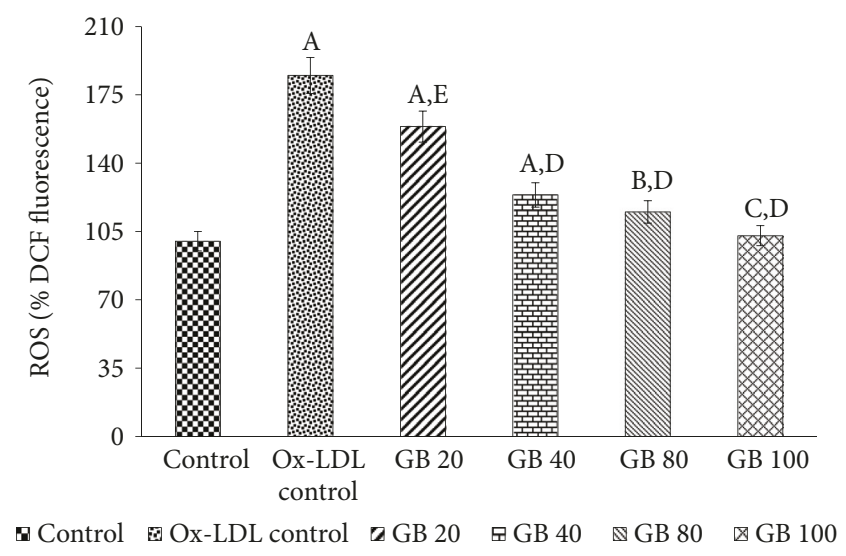

(b)

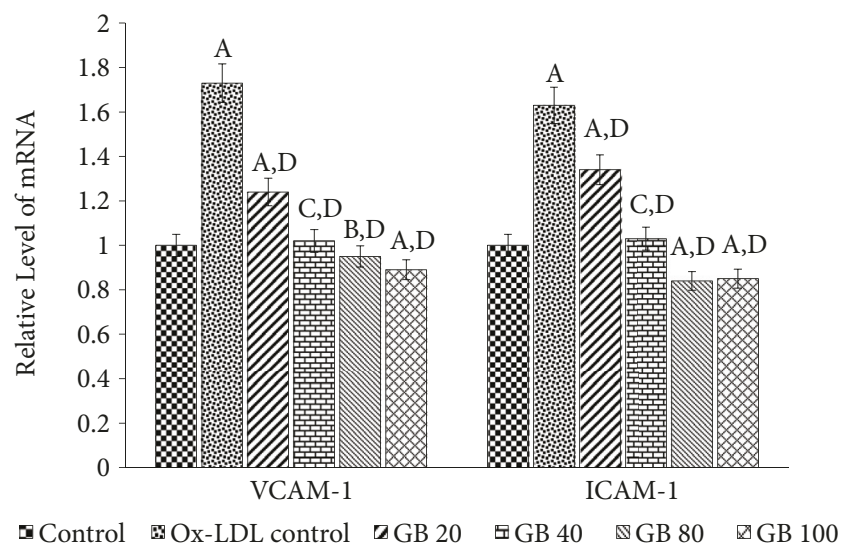

(d)

FIgURE 3: (a) Ox-LDL treatment induces the ROS generation in HUVECs. The cultured HUVECs cells were either treated with native LDL or Ox-LDL $(25,50,75$, and $100 \mu \mathrm{g} / \mathrm{ml})$ for determination of ROS generation in terms of \% DCFDA fluorescence. Significantly different from native LDL at ${ }^{\mathrm{A}} \mathrm{p}<0.001$. (b) Ginkgolide B suppresses ROS generation in Ox-LDL-treated HUVECs. ROS level in terms of \%DCFDA fluorescence was quantified by the pretreatment of HUVECs with different concentrations of Ginkgolide B (20-100 $\mathrm{gg} / \mathrm{ml})$ for $24 \mathrm{~h}$ followed by the treatment of Ox-LDL $(75 \mu \mathrm{g} / \mathrm{ml})$ for another $6 \mathrm{~h}$. Significantly different from control HUVECs at ${ }^{\mathrm{A}} \mathrm{p}<0.001$. Significantly different from control HUVECs at ${ }^{\mathrm{B}} \mathrm{p}<0.01$. Nonsignificantly different from control HUVECs at ${ }^{\mathrm{C}} \mathrm{p}>0.05$. Significantly different from Ox-LDL at ${ }^{\mathrm{D}} \mathrm{p}<0.001$. Significantly different from Ox-LDL at ${ }^{\mathrm{E}} \mathrm{p}<0.01$. (c) Ox-LDL treatment upregulates the expression of ICAM-1 and VCAM-1 in HUVECs. The cultured HUVECs cells were either treated with native LDL or Ox-LDL $(25,50,75$, and $100 \mu \mathrm{g} / \mathrm{ml})$ for the ICAM-1 and VCAM-1 expression analysis. Significantly different from native LDL at ${ }^{\mathrm{A}} \mathrm{p}<0.001$. Significantly different from native LDL at ${ }^{\mathrm{B}} \mathrm{p}<0.01$. (d) Ginkgolide B ameliorates endothelial dysfunction by suppressing expression of ICAM-1 and VCAM-1 in Ox-LDL-treated HUVECs. Cells were pretreated with 20, 40, 80, and $100 \mu \mathrm{g} / \mathrm{ml}$ of Ginkgolide B for $24 \mathrm{~h}$ and then exposed to Ox-LDL $(75 \mu \mathrm{g} / \mathrm{ml})$ for another $24 \mathrm{~h}$. The cells were harvested and transcript levels of ICAM-1 and VCAM-1 were examined by qRT-PCR. Significantly different from control HUVECs at ${ }^{\text {A }} \mathrm{p}<0.001$. Significantly different from control HUVECs at ${ }^{B} \mathrm{p}<0.01$. Nonsignificantly different from control HUVECs at ${ }^{\mathrm{C}} \mathrm{p}>0.05$. Significantly different from $\mathrm{Ox}-\mathrm{LDL}$ at ${ }^{\mathrm{D}} \mathrm{p}<0.001$. All the values in (a), (b), (c), and (d) have been expressed as mean \pm SEM of three independent experiments.

Thr459 amino acid residues (Figure 5(b)).The most important finding from our in silico study was the fact that both the ligands (Ginkgolide B and Atorvastatin) were surrounded by nine common amino acid residues of PCSK-9 (Arg357, Arg458, Val460, Trp461, Ser462, ALA463, Val474, Ala475, and Arg476). Furthermore, these complexes of Ginkgolide B and Atorvastatin with PCSK-9 were used to interact with EGF-A portion of LDL-R via PPI studies, which demonstrated that Ginkgolide B destabilizes the PCSK-9-EGF-A complex (ZDOCK Score: 1031.026), whereas Atorvastatin aids in stabilization of PCSK-9-EGF-A complex (ZDOCK Score: 1071.570), when the ZDOCK Score for both these compounds was compared with PCSK-9-EGF-A-complex without any ligand (ZDOCK Score: 1055.178) (Figure 6).

\section{Discussion}

Atherosclerosis is reckoned as a chronic inflammatory ailment and is greatly assisted by vascular EC dysfunction $[3,11,25]$. PCSK-9 regulates the receptor-mediated LDL internalization into hepatocytes and subsequent atherogenic load in the vessels $[26,27]$. Genetic defects in PCSK-9 lead to the establishment of familial hypercholesterolemia 


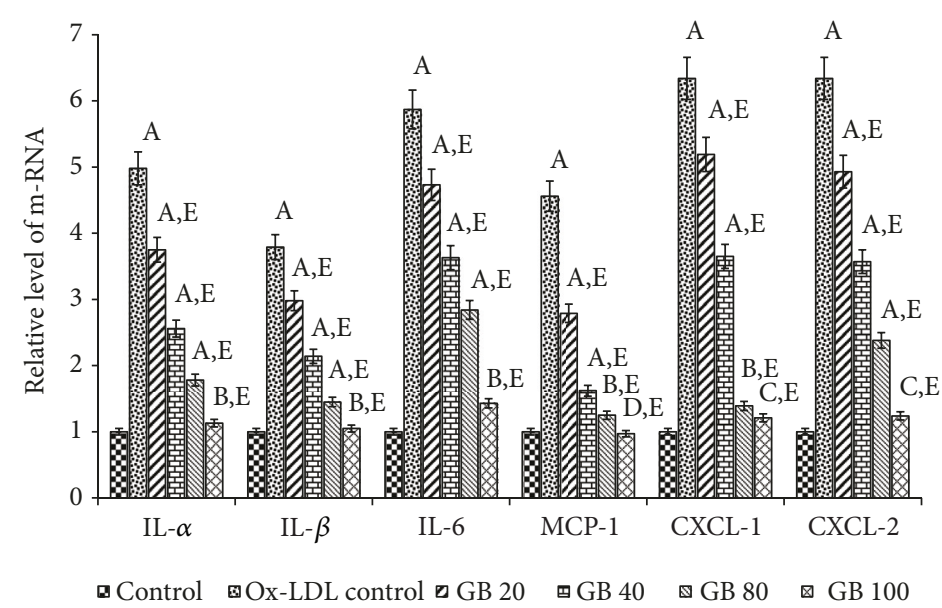

(a)

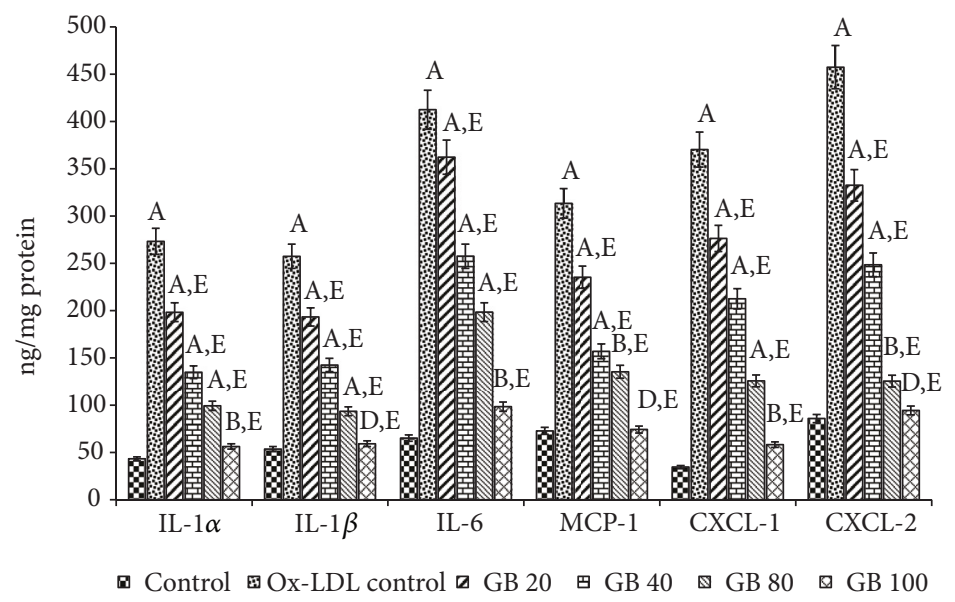

(b)

FIgURE 4: (a) Ginkgolide B downregulates the expression of inflammatory cytokines and chemokines in Ox-LDL-treated HUVECs. HUVECs were grown in six-well plates for $24 \mathrm{~h}$ and treated with different concentrations of Ginkgolide B $(20-100 \mu \mathrm{g} / \mathrm{ml})$ for $24 \mathrm{~h}$ followed by the treatment of Ox-LDL $(75 \mu \mathrm{g} / \mathrm{ml})$ for another $24 \mathrm{~h}$. The cells were harvested and the expression of cytokines (IL- $1 \alpha$, IL- $1 \beta$, \& IL- 6 ) and chemokines (MCP-1, CXCL-1, \& CXCL-2) was examined by qRT-PCR analysis. (b) Ginkgolide B inhibited inflammatory protein expression in Ox-LDLtreated HUVECs. Cells were grown in six-well plates for $24 \mathrm{~h}$ and treated with different concentrations of Ginkgolide B (20-100 $\mu \mathrm{g} / \mathrm{ml})$ for $24 \mathrm{~h}$ followed by the treatment of Ox-LDL $(75 \mu \mathrm{g} / \mathrm{ml})$ for another $24 \mathrm{~h}$. The cells were harvested and cell lysates were prepared. Protein levels of different cytokines (IL-1 $\alpha$, IL-1 $\beta$, \& IL-6) and chemokines (MCP-1, CXCL-1, \& CXCL-2) were examined by ELISA kits. The levels of statistical significance for both (a) and (b) are significantly different from control HUVECs at ${ }^{\mathrm{A}} \mathrm{p}<0.001$. Significantly different from control HUVECs at ${ }^{B} \mathrm{p}<0.01$. Significantly different from control HUVECs at ${ }^{C} \mathrm{p}<0.05$. Nonsignificantly different from control HUVECs at ${ }^{\mathrm{D}} \mathrm{p}>0.05$. Significantly different from Ox-LDL at ${ }^{\mathrm{E}} \mathrm{p}<0.001$. All the values in both (a) and (b) have been expressed as mean \pm SEM of three independent experiments.

which ultimately progresses into AS [28, 29]. Following its synthesis and secretion, PCSK-9 combines to extracellular EGF-A domain of LDL-R and facilitates the lysosomemediated catalysis of LDL-R, resulting in lesser no. of LDL-Rs available on hepatocytes for further LDL clearance [19, 3032]. Together with these findings, other reports also advocate the ability of PCSK-9 to regulate the circulatory LDL-C [3335].

It is also well reckoned that both PCSK-9 and LDL-R are coexpressed in many cell types and their gene transcription is under control of SREBP-2 [35-37]. Therefore, in the current study, we did find a decline in the PCSK-9 expression by
Ginkgolide B supplementation in HUVECs. In a recent study, Ox-LDL has been found to stimulate PCSK-9 expression, indicating that perhaps inflammatory response aids in the earlier PCSK-9 activation [5]. Very few natural products, i.e., berberine and lycopene, have been reported to influence the expression of hepatocyte nuclear factor- $1 \alpha$ (HNF-1 $\alpha$ ) and SREBP-2, thereby regulating the PCSK-9 menace [35, 38]. Thus, in accordance with the previous studies, we also concluded that Ginkgolide B exerts protective effect against atherosclerosis via limiting the PCSK-9 expression. Furthermore, we observed a decline in Ox-LDL-induced expression of SREBP-2 in Ginkgolide B-treated HUVECs which could 


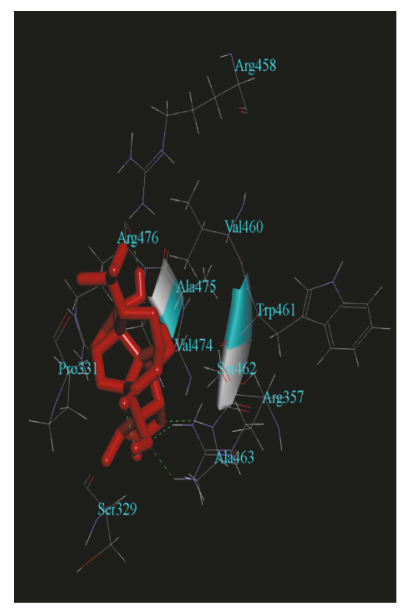

(a)

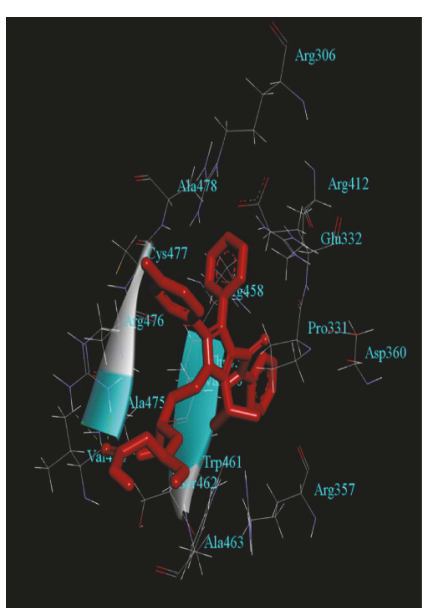

(b)

FIGURE 5: Molecular informatics studies of Ginkgolide B and Atorvastatin with PCSK-9. (a) Interaction of Ginkgolide B (represented as red ball-stick model) with PCSK-9 (PDB I.D.: 2p4e) residues showed the binding energy $(\Delta \mathrm{G})$ of $-7.13 \mathrm{Kcal} / \mathrm{mol}$. (b) Interaction of Atorvastatin (represented as red ball-stick model) with the residues of PCSK-9 showed the binding energy $(\Delta \mathrm{G})$ of $-7.02 \mathrm{Kcal} / \mathrm{mol}$.

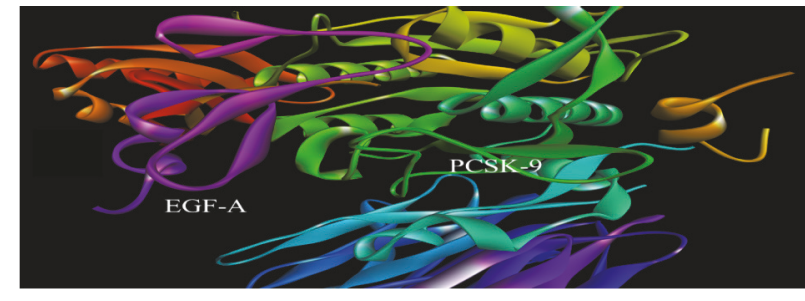

(a)

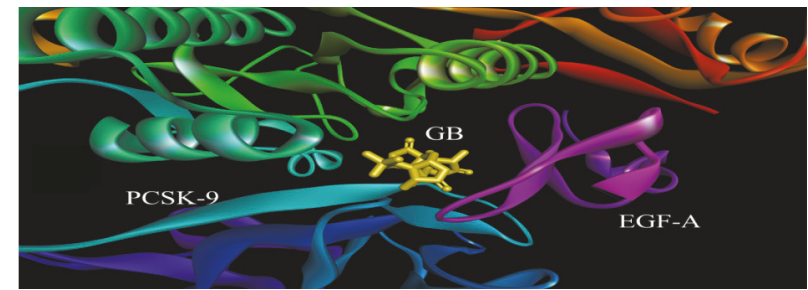

(b)

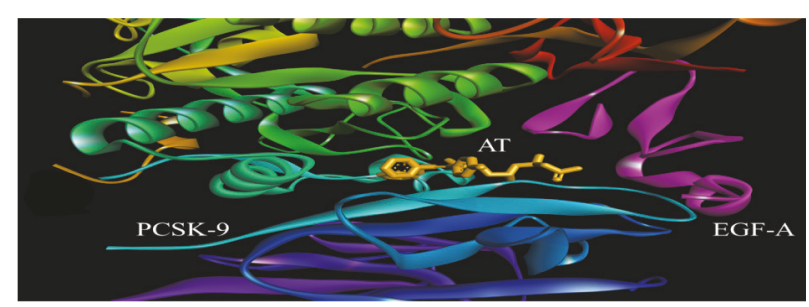

(c)

FIGURE 6: Ginkgolide B reduces the affinity of PCSK-9 to complex with EGF-A-like repeats of LDL-R. (a) PCSK-9-EGF-A-complex (PCSK9 chains have been represented as ribbon structures in various colors, while EGF-A of LDL-R has been represented as purple ribbon-like structure). (b) Ginkgolide B-PCSK-9-EGF-A-complex (Ginkgolide B has been represented in yellow as ball-stick molecule). (c) AtorvastatinPCSK-9-EGF-A-complex (Atorvastatin has been represented in yellow as ball-stick molecule).

be correlated with the decline in PCSK-9 expression in HUVECs.

Additionally, our results have also shown an interesting phenomenon that Ginkgolide B treatment augmented the expression of LDL-R along with suppression of PCSK-9 which was in contradiction to reports where statins upregulated the expression of both PCSK-9 and LDL-R, which ultimately limited the beneficial effects of statins $[19,38]$. Moreover, we have also shown that Ginkgolide B treatment leads to inhibition of SREBP-2, which is responsible for the regulation of both PCSK-9 and LDL-R gene. On the other hand, the pharmacological effect of statins is achieved by upregulation of both PCSK-9 and LDL-R expression as their expression is governed by a common motif, sterol regulatory element (SRE-1), located in the LDL$\mathrm{R}$ and PCSK-9 promoters, limiting the beneficial effect of statins to lower LDL-C level [35, 39-41]. Interestingly, in our study, the downregulation of SREBP-2 did not suppress/affect the LDL-R expression in HUVECs, rather it was augmented by Ginkgolide B treatment; thus, the result suggested that Ginkgolide B could regulate the LDL-R expression in HUVECs by a sterol-independent mechanism. These findings are in well agreement with previous reports [19, 38]. These findings demonstrate that Ginkgolide B exerts potent antiatherogenic effects via modes distinct to that of statins. 
Moreover, the results from our in silico analysis did show that Ginkgolide B possesses the ability to interact with PCSK-9 in a somewhat comparable manner as atorvastatin does with nine common hydrophobic residues, i.e., Arg357, Arg458, Val460, Trp461, Ser462, ALA463, Val474, Ala475, and Arg476. Furthermore, the binding energies for both compounds $(\Delta \mathrm{G}:-7.13$ and $-7.02 \mathrm{Kcal} / \mathrm{mol}$, respectively) also confirmed their comparable interaction against PCSK9 binding region. Further, our PPI studies showed very surprising results that Ginkgolide B destabilizes/prevents the PCSK-9-EGF-A complex, while atorvastatin facilitated the binding of PCSK-9 with EGF-A portion of LDL-R. This data is in well accordance with the previously published report demonstrating the ability of Atorvastatin to stimulate PCSK9 to make a more stable PCSK-9-EGF-A-complex than it does in the absence of Atorvastatin [19].

Overexpression of LOX-1 in distinct physiological circumstances induces AS progression in hyperlipidemic mice via enhanced rate of Ox-LDL uptake and subsequent endothelial dysfunction [42]. Conversely, mice, lacking LOX1 gene, have shown to be negatively associated with the incidence of the atherosclerosis regardless of their highcholesterol-rich diet [12]. In order to cope with these consequences, we assessed the protective role of Ginkgolide B in Ox-LDL-triggered LOX-1 expression and reported that it significantly diminishes the LOX-1 expression in HUVECs. Furthermore, we also observed a low accumulation of TC and FC in Ox-LDL-induced cells when pretreated with Ginkgolide B which could be attributed to the diminished expression and activity of LOX-1. Our results have shown that both PCSK-9 and LOX-1 expression is enhanced in HUVECs by Ox-LDL stimulus. Ding et al. also showed a cross-talk between PCSK-9 and LOX-1 that may be of great importance in predicting atherogenic manifestations [5]. Similarly, upon PCSK-9 knockdown or knockout, LOX-1 was inhibited significantly [12]. Thus, PCSK-9 inhibition strategies could also inactivate LOX-1 which was well justified with a study that established the attenuation of Ox-LDL induced both PCSK-9 \& LOX-1 expression [5], which further suggested the therapeutic importance of this compound in AS.

Furthermore, Ox-LDL is well reckoned to promote ROS generation and in the same vein, NOX-4 is also known to generate ROS, an established risk factor for AS [43, 44]. NOX4 is highly expressed in different cells including ECs [45]. Similarly, we also reported that incubation with oxidatively modified-LDL markedly upregulated the NOX-4 expression. The results in turn illustrated that Ox-LDL promoted the expression of PCSK9, affected LDLR-mediated signaling pathway, participated in oxidative stress, and induced inflammatory cascade reaction at different levels. It is suggested that there is cross-regulation between molecules. Further, Ginkgolide B significantly restored the NOX-4 expression along with the diminished ROS level in HUVECs. Based on these findings, we refer that Ginkgolide B-mediated low level of ROS might be attributed to its ability to suppress NOX4 mRNA, which has been in well agreement with previous report [46]. Our results showed that Ginkgolide B could weaken the effect of Ox-LDL in the whole process, and Ginkgolide B affected the function of PCSK9.
Activation of ECs induces several adhesion proteins, i.e., MCP-1, ICAM-1, and VCAM-1. On the other hand, uptake of Ox-LDL by macrophages leads to their transformation into the foam cells, which are reckoned to retrigger inflammatory cascades, leading to endothelial dysfunction and subsequent atherosclerosis plaque formation [14, 47-49]. The results of our study have clearly documented that overexpression of adhesion molecules ICAM-1 and VCAM-1 on ECs induced by Ox-LDL was attenuated by Ginkgolide B treatment as well as the expression of ILs, MCP-1, CXCL-1, and CXCL-2 was also kept in check by Ginkgolide B. It is revealed that Ginkgolide $B$ improves the inflammatory cascade reaction activated by Ox-LDL by regulating PCSK9-LDLR signaling pathway.

PCSK-9 inhibition either by knockdown approaches or mice lacking this gene has been found to resist against the $\mathrm{Ox}^{-}$ LDL as well as lipopolysaccharide (LPS) triggered systemic responses $[2,50]$. On the other hand, overexpression of PCSK-9 was found to be associated with robust inflammatory response to LPS in macrophages [51]. The above findings uncovered the role of PCSK-9 in the atherosclerotic plaque formation via enhanced localized inflammation, monocyte infiltration, and monocyte transformation. Since we have shown that Ox-LDL can stimulate HUVECs to secrete PCSK-9 abundantly, thus, we can deduce an interesting inference from our results that activation and overexpression of PCSK-9 might participate in the initiation of the above observed inflammatory cascade in Ox-LDL-stimulated HUVECs. Conclusively, the results of our current study signify that Ginkgolide B-mediated inhibition of PCSK-9 expression in HUVECs could suppress these proinflammatory cascades in the atherosclerotic plaques and, thus, could possibly play therapeutic role in the alleviation of sufferings, up to some part, from AS.

\section{Conclusion}

In conclusion, our in vitro findings strongly suggested that Ginkgolide B could potentially suppress PCSK-9 along with SREBP-2 expression and, conversely, could augment the LDL$\mathrm{R}$ expression. Ginkgolide B also inhibits LOX-1 expression and unusual lipid accumulation in ECs as well as significantly decreases NOX-4 expression and ROS generation in ECs. Moreover, Ginkgolide B also downregulated the expression of ICAM-1 and VCAM-1 in ECs and exhibited potent antiinflammatory activity in Ox-LDL-induced HUVECs. Furthermore, our PPI studies demonstrated that Ginkgolide B destabilizes the PCSK-9-EGF-A complex, whereas Atorvastatin stabilizes the PCSK-9-EGF-A complex, when the ZDOCK scores for these compounds were compared with PCSK-9-EGF-A-complex without any ligand. Finally, owing to its protective role against the progression of atherosclerosis, further in vivo studies are warranted to establish its clinical significance.

\section{Data Availability}

The data used to support the findings of this study are available from the corresponding author upon request. 


\section{Conflicts of Interest}

The authors declare that they have no conflicts of interest regarding the publication of this paper.

\section{Funding}

This research received no external funding and the APC was funded by the authors.

\section{References}

[1] R. Ross and B. Dodet, "Atherosclerosis is an inflammatory disease," American Heart Journal, vol. 138, no. 5, pp. S419-S420, 1999.

[2] Z. Tang, L. Jiang, J. Peng et al., "PCSK9 siRNA suppresses the inflammatory response induced by oxLDL through inhibition of NF- $\kappa \mathrm{B}$ activation in THP-1-derived macrophages," International Journal of Molecular Medicine, vol. 30, no. 4, pp. 931-938, 2012.

[3] J. Li, X. Liang, Y. Wang, Z. Xu, and G. Li, "Investigation of highly expressed PCSK9 in atherosclerotic plaques and oxLDL-induced endothelial cell apoptosis," Molecular Medicine Reports, vol. 16, no. 2, pp. 1817-1825, 2017.

[4] B. Cariou, C. Le May, and P. Costet, "Clinical aspects of PCSK9," Atherosclerosis, vol. 216, no. 2, pp. 258-265, 2011.

[5] Z. Ding, S. Liu, X. Wang et al., "Cross-Talk between LOX-1 and PCSK9 in vascular tissues," Cardiovascular Research, vol. 107, no. 4, pp. 556-567, 2015.

[6] T. P. Leren, "Sorting an LDL receptor with bound PCSK9 to intracellular degradation," Atherosclerosis, vol. 237, no. 1, pp. 7681, 2014.

[7] C.-Y. Wu, Z.-H. Tang, L. Jiang, X.-F. Li, Z.-S. Jiang, and L.-S. Liu, "PCSK9 siRNA inhibits HUVEC apoptosis induced by ox-LDL via Bcl/Bax-caspase9-caspase3 pathway," Molecular and Cellular Biochemistry, vol. 359, no. 1-2, pp. 347-358, 2012.

[8] M. Ruscica, N. Ferri, F. Fogacci et al., "Circulating levels of proprotein convertase subtilisin/kexin type 9 and arterial stiffness in a large population sample: data from the brisighella heart study," Journal of the American Heart Association, vol. 6, no. 5, Article ID e005764, 2017.

[9] C. Ricci, M. Ruscica, M. Camera et al., "PCSK9 induces a proinflammatory response in macrophages," Scientific Reports, vol. 8, no. 1, article no. $2267,2018$.

[10] N. Ferri, G. Tibolla, A. Pirillo et al., "Proprotein convertase subtilisin kexin type 9 (PCSK9) secreted by cultured smooth muscle cells reduces macrophages LDLR levels," Atherosclerosis, vol. 220, no. 2, pp. 381-386, 2012.

[11] P. Libby, P. M. Ridker, and A. Maseri, "Inflammation and atherosclerosis," Circulation, vol. 105, no. 9, pp. 1135-1143, 2002.

[12] J. L. Mehta, N. Sanada, C. P. Hu et al., "Deletion of LOX1 reduces atherogenesis in LDLR knockout mice fed high cholesterol diet," Circulation Research, vol. 100, no. 11, pp. 1634$1642,2007$.

[13] A. Akhmedov, I. Rozenberg, F. Paneni et al., "Endothelial overexpression of LOX-1 increases plaque formation and promotes atherosclerosis in vivo," European Heart Journal, vol. 35, no. 40, pp. 2839-2848, 2014.

[14] G. Krishnaswamy, J. Kelley, L. Yerra, J. K. Smith, and D. S. Chi, "Human endothelium as a source of multifunctional cytokines: molecular regulation and possible role in human disease,"
Journal of Interferon \& Cytokine Research, vol. 19, pp. 91-104, 1999.

[15] A. D. Grypioti, G. Kostopanagiotou, C. A. Demopoulos, A. Roussos, and M. Mykoniatis, "Platelet activating factor (PAF) antagonism with ginkgolide $\mathrm{B}$ protects the liver against acute injury. Importance of controlling the receptor of PAF," Digestive Diseases and Sciences, vol. 53, no. 4, pp. 1054-1062, 2008.

[16] H. Kälvegren, J. Andersson, M. Grenegård, and T. Bengtsson, "Platelet activation triggered by Chlamydia pneumoniae is antagonized by 12-lipoxygenase inhibitors but not cyclooxygenase inhibitors," European Journal of Pharmacology, vol. 566, pp. 20-27, 2007.

[17] Z. Feng, X. Yang, L. Zhang et al., "Ginkgolide B ameliorates oxidized low-density lipoprotein-induced endothelial dysfunction via modulating Lectin-like ox-LDL-receptor-1 and NADPH oxidase 4 expression and inflammatory cascades," Phytotherapy Research, vol. 32, pp. 2417-2427, 2018.

[18] H. Wieland and D. Seidel, "A simple specific method for precipitation of low density lipoproteins," Journal of Lipid Research, vol. 24, no. 7, pp. 904-909, 1983.

[19] S. Sultan Alvi, I. A. Ansari, I. Khan, J. Iqbal, and M. S. Khan, "Potential role of lycopene in targeting proprotein convertase subtilisin/kexin type-9 to combat hypercholesterolemia," Free Radical Biology \& Medicine, vol. 108, pp. 394-403, 2017.

[20] A. E. Scoccia, M. S. Molinuevo, A. D. McCarthy, and A. M. Cortizo, "A simple method to assess the oxidative susceptibility of low density lipoproteins," BMC Clinical Pathology, vol. 1, no. $1,2001$.

[21] M. M. Bradford, "A rapid and sensitive method for the quantitation of microgram quantities of protein utilizing the principle of protein dye binding," Analytical Biochemistry, vol. 72, no. 1-2, pp. 248-254, 1976.

[22] S. Zhang, B. Chen, W. Wu, L. Bao, and R. Qi, "Ginkgolide $B$ reduces inflammatory protein expression in oxidized lowdensity lipoprotein-stimulated human vascular endothelial cells," Journal of Cardiovascular Pharmacology, vol. 57, no. 6, pp. 721-727, 2011.

[23] C. Rouault, V. Pellegrinelli, R. Schilch et al., "Roles of chemokine ligand-2 (CXCL2) and neutrophils in influencing endothelial cell function and inflammation of human adipose tissue," Endocrinology, vol. 154, no. 3, pp. 1069-1079, 2013.

[24] A. Farooqui, F. Khan, I. Khan, and I. A. Ansari, "Glycyrrhizin induces reactive oxygen species-dependent apoptosis and cell cycle arrest at G0/G1 in HPV18+ human cervical cancer HeLa cell line," Biomedicine \& Pharmacotherapy, vol. 97, pp. 752-764, 2018.

[25] G. K. Hansson, "Mechanisms of disease: inflammation, atherosclerosis, and coronary artery disease," The New England Journal of Medicine, vol. 352, no. 16, pp. 1626-1695, 2005.

[26] J. D. Horton, J. C. Cohen, and H. H. Hobbs, "Molecular biology of PCSK9: its role in LDL metabolism," Trends in Biochemical Sciences, vol. 32, no. 2, pp. 71-77, 2007.

[27] N. G. Seidah, "PCSK9 as a therapeutic target of dyslipidemia," Expert Opinion on Therapeutic Targets, vol. 13, no. 1, pp. 19-28, 2009.

[28] L. Zhang, F. Yuan, P. Liu et al., "Association between PCSK9 and LDLR gene polymorphisms with coronary heart disease: Casecontrol study and meta-analysis," Clinical Biochemistry, vol. 46, no. 9, pp. 727-732, 2013.

[29] N. Q. Wu and J. J. Li, "PCSK9 gene mutations and low density lipoprotein cholesterol," Clinica Chimica Acta, vol. 431, pp. 148153, 2014 
[30] Y. Wang, Y. Huang, H. H. Hobbs, and J. C. Cohen, "Molecular characterization of proprotein convertase subtilisin/kexin type 9-mediated degradation of the LDLR," Journal of Lipid Research, vol. 53, no. 9, pp. 1932-1943, 2012.

[31] D.-W. Zhang, T. A. Lagace, R. Garuti et al., "Binding of proprotein convertase subtilisin/kexin type 9 to epidermal growth factor like repeat A of low-density lipoprotein receptor decreases receptor recycling and increases degradation," The Journal of Biological Chemistry, vol. 282, no. 25, pp. 18602-18612, 2007.

[32] M. C. McNutt, H. J. Kwon, C. Chen, J. R. Chen, J. D. Horton, and T. A. Lagace, "Antagonism of secreted PCSK9 increases low density lipoprotein receptor expression in HepG2 cells," The Journal of Biological Chemistry, vol. 284, no. 16, pp. 10561-10570, 2009.

[33] G. Lambert, N. Ancellin, F. Charlton et al., "Plasma PCSK9 concentration correlates with LDL and total cholesterol in diabetic patients and are decreased by fenofi brate treatment," Clinical Chemistry, vol. 54, no. 6, pp. 1038-1045, 2008.

[34] A. Grefhorst, M. C. McNutt, T. A. Lagace, and J. D. Horton, "Plasma PCSK9 preferentially reduces liver LDL receptors in mice," Journal of Lipid Research, vol. 49, no. 6, pp. 1303-1311, 2008.

[35] B. Dong, M. Wu, H. Li et al., "Strong induction of PCSK9 gene expression through HNF1 $\alpha$ and SREBP2: mechanism for the resistance to LDL-cholesterol lowering effect of statins in dyslipidemic hamsters," Journal of Lipid Research, vol. 51, no. 6, pp. 1486-1495, 2010.

[36] G. Dubuc, A. Chamberland, H. Wassef et al., "Statins upregulate PCSK9, the gene encoding the proprotein convertase neural apoptosis-regulated convertase-1 implicated in familial hypercholesterolemia," Arteriosclerosis, Thrombosis, and Vascular Biology, vol. 24, no. 8, pp. 1454-1459, 2004.

[37] J. J. Hyun, H.-S. Lee, K.-S. Kim, Y.-K. Kim, D. Yoon, and W. P. Sahng, "Sterol-dependent regulation of proprotein convertase subtilisin/kexin type 9 expression by sterol-regulatory element binding protein-2," Journal of Lipid Research, vol. 49, no. 2, pp. 399-409, 2008

[38] S. S. Alvi, I. A. Ansari, M. K. Ahmad, J. Iqbal, and M. S. Khan, "Lycopene amends LPS induced oxidative stress and hypertriglyceridemia via modulating PCSK-9 expression and Apo-CIII mediated lipoprotein lipase activity," Biomedicine \& Pharmacotherapy, vol. 96, pp. 1082-1093, 2017.

[39] H. E. Careskey, R. A. Davis, W. E. Alborn, J. S. Troutt, G. Cao, and R. J. Konrad, "Atorvastatin increases human serum levels of proprotein convertase subtilisin/kexin type 9," Journal of Lipid Research, vol. 49, no. 2, pp. 394-398, 2008.

[40] R. J. Schmidt, T. P. Beyer, W. R. Bensch et al., "Secreted proprotein convertase subtilisin/kexin type 9 reduces both hepatic and extrahepatic low-density lipoprotein receptors in vivo," Biochemical and Biophysical Research Communications, vol. 370, no. 4, pp. 634-640, 2008.

[41] G. Cao, Y.-W. Qian, M. C. Kowala, and R. J. Konrad, "Further LDL cholesterol lowering through targeting PCSK9 for coronary artery disease," Endocrine, Metabolic \& Immune Disorders-Drug Targets, vol. 8, no. 4, pp. 238-243, 2008.

[42] K. Inoue, Y. Arai, H. Kurihara, T. Kita, and T. Sawamura, "Over expression of lectin-like oxidized low-density lipoprotein receptor-1 induces intramyocardial vasculopathy in apolipoprotein E-null mice," Circulation Research, vol. 97, no. 2, pp. 176184, 2005.
[43] L. Cominacini, A. Fratta Pasini, U. Garbin et al., "Oxidized low density lipoprotein (ox-LDL) binding to ox-LDL receptor-1 in endothelial cells induces the activation of NF kappaB through an increased production of intracellular reactive oxygen species," The Journal of Biological Chemistry, vol. 275, no. 17, pp. 12633-12638, 2000.

[44] A. E. Vendrov, N. R. Madamanchi, X.-L. Niu et al., "NADPH oxidases regulate CD44 and hyaluronic acid expression in thrombin-treated vascular smooth muscle cells and in atherosclerosis," The Journal of Biological Chemistry, vol. 285, no. 34, pp. 26545-26557, 2010.

[45] H. Xu, C. Goettsch, N. Xia et al., "Differential roles of PKC alpha and PKC epsilon in controlling the gene expression of Nox4 in human endothelial cells," Free Radical Biology \& Medicine, vol. 44, pp. 1656-1667, 2008.

[46] R. Li, B. Chen, W. Wu, L. Bao, J. Li, and R. Qi, "Ginkgolide B suppresses intercellular adhesion molecule-1 expression via blocking nuclear factor-kappa B activation in human vascular endothelial cells stimulated by oxidized low-density lipoprotein," Journal of Pharmaceutical Sciences, vol. 110, pp. 362-369, 2009.

[47] T. A. Angelovich, A. C. Hearps, and A. Jaworowski, "Inflammation-induced foam cell formation in chronic inflammatory disease," Immunology \& Cell Biology, vol. 93, no. 8, pp. 683-693, 2015.

[48] M. Ekstrand, M. G. Trajkovska, J. Perman-Sundelin et al., "Imaging of intracellular and extracellular ROS levels in atherosclerotic mouse aortas ex vivo: Effects of lipid lowering by diet or atorvastatin," PLoS ONE, vol. 10, no. 6, Article ID e0130898, 2015.

[49] A. Manea, S.-A. Manea, A. M. Gan et al., "Human monocytes and macrophages express NADPH oxidase 5; A potential source of reactive oxygen species in atherosclerosis," Biochemical and Biophysical Research Communications, vol. 461, no. 1, pp. 172179, 2015.

[50] K. R. Walley, K. R. Thain, J. A. Russell et al., "PCSK9 is a critical regulator of the innate immune response and septic shock outcome," Science Translational Medicine, vol. 6, no. 258, pp. 258-ra143, 2014.

[51] I. Giunzioni, H. Tavori, R. Covarrubias et al., "Local effects of human PCSK9 on the atherosclerotic lesion," The Journal of Pathology, vol. 238, no. 1, pp. 52-62, 2016. 

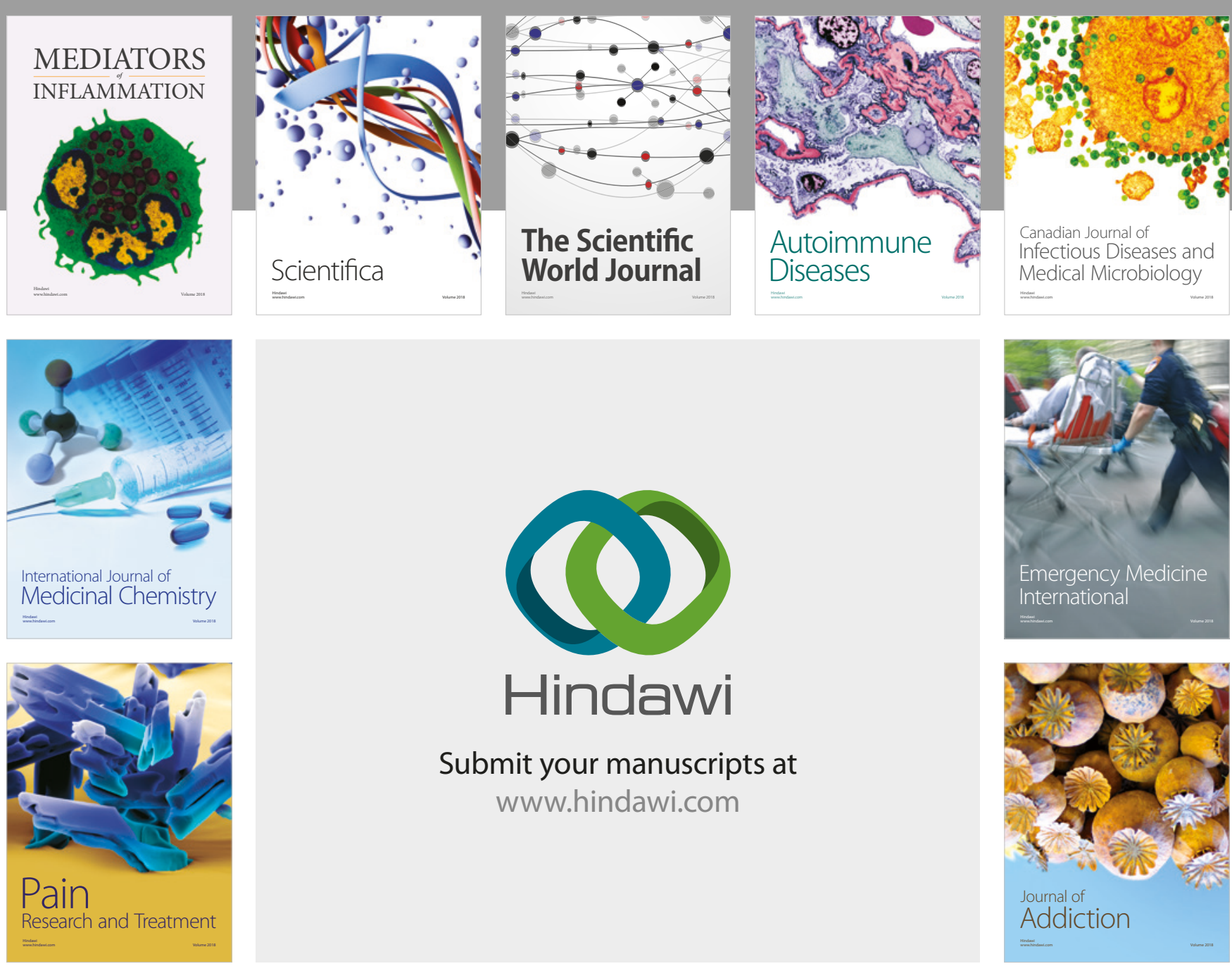

Canadian Journal of
Infectious Diseases and Medical Microbiology

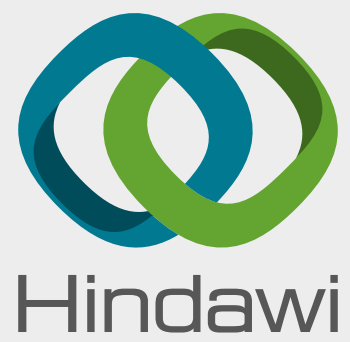

Submit your manuscripts at

www.hindawi.com
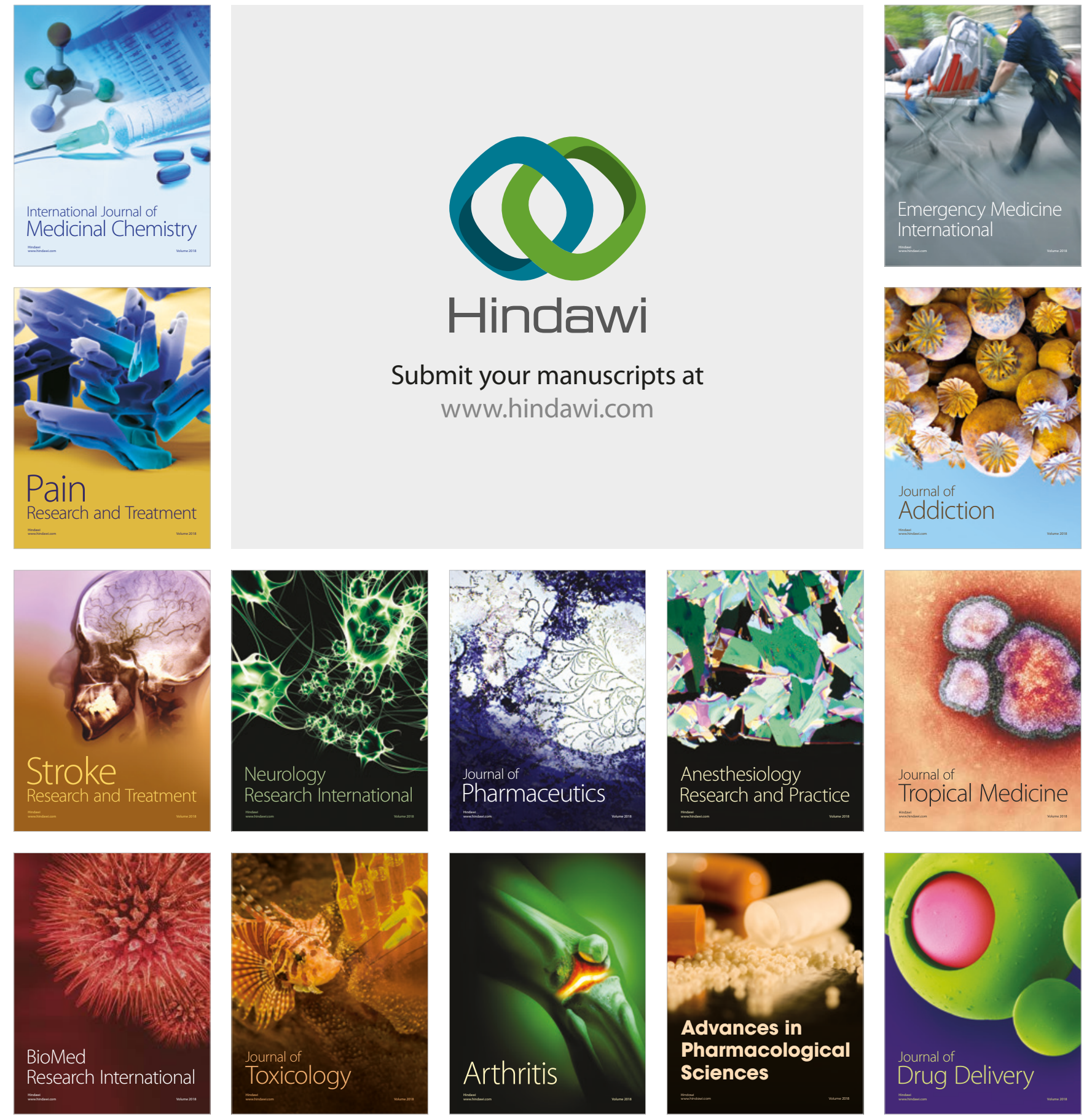